RESEARCH PAPER

\title{
Public health measures to reduce smoking prevalence in the UK: how many lives could be saved?
}

\author{
S Lewis, D Arnott, C Godfrey, J Britton
}

Tobacco Control 2005;14:251-254. doi: 10.1136/tc.2005.011064

See end of article for authors' affiliations .....................

Correspondence to: Professor John Britton, University of Nottingham, Division of Epidemiology and Public Health, City Hospital, Nottingham NG5 IPB, UK; j.britton@virgin. net

Received 2 January 2005 Accepted 13 April 2005

\begin{abstract}
Objective: To estimate the number of deaths that could be prevented in the UK by implementing population strategies to reduce smoking prevalence.

Design: A prospective analysis of future mortality using recent national smoking prevalence data and relative risks of mortality in current smokers, ex-smokers, and never-smokers.

Population: Smokers in the UK.

Interventions: Population measures of proven effectiveness assumed to reduce smoking prevalence by 1 percentage point per year for 10 years, or alternatively by $13 \%$ over 19 years 1 percentage point per annum for seven years, 0.5 percentage point per annum for 12 years) as considered to be achievable in a recent report to the UK Chancellor of the Exchequer.

Main outcome measure: Estimated deaths from smoking prevented in the 35-75 year age group.

Results: Reducing the prevalence of smoking by 1 percentage point each year for 10 years would prevent 69049 deaths at ages between 35 and 74 years during that period. The model of reduction by $13 \%$ over 19 years would prevent 54308 and 194493 deaths in 10 and 19 years, respectively. Continued prevalence reductions at the current rate of 0.4 percentage points each year will prevent 23192 deaths over 10 years.

Conclusions: Full implementation of simple population measures to encourage smoking cessation could prevent substantial numbers of deaths in the UK.
\end{abstract}

S moking causes more death and disability in the UK than any other avoidable factor. About $24 \%$ of UK adults or 12 million people are current regular smokers, ${ }^{1}$ and of those who continue to smoke, half will die prematurely from a disease caused by their smoking. ${ }^{2}$ Reducing smoking prevalence is therefore crucial to improving the public health. Major reductions in prevalence were achieved in the UK between 1960 and 1990, but throughout the 1990s there was relatively little change. ${ }^{3}$

The UK government has now banned all tobacco advertising and invested heavily in providing cessation services for smokers who want to quit. New surveys suggest that the prevalence of smoking has now begun to fall again, at about 0.4 percentage points per year. ${ }^{14}$ Experience from other countries indicates, however, that much greater reductions could be achieved by implementing further simple but highly cost effective population measures to encourage cessation. These include progressive rises in cigarette price, sustained health promotion campaigns, effective health warnings on cigarette packs, and legislation to make all public and work places smoke-free. . $^{5-11}$

To estimate the potential public health impact of full implementation of these strategies we have calculated the number of deaths expected to be prevented according to three scenarios of prevalence decline over the next 10 years. These comprise first, a continued decline at the current rate of 0.4 percentage points per year, reflecting the likely maximum effect of no further intervention; second, decline at a rate of l percentage point per year, which we propose to be achievable if all available public health interventions were to be applied; and third, decline according to the "fully engaged scenario" defined in a recent report on future priorities for public health commissioned by the UK government, authored by Derek Wanless. ${ }^{12}$ This report suggested that full implementation of available population strategies would reduce smoking prevalence by 1 percentage point per year for seven years, and then by half a percentage point per year for a further 12 years. ${ }^{12}$

\section{METHODS}

We used population data from the 2001 UK census ${ }^{13}$ and smoking prevalence figures from the 2003 Omnibus Survey ${ }^{1}$ to estimate the numbers of male and female smokers currently alive in the UK at each year of age up to 75 . We then combined information on the proportions of nonsmokers, ex-smokers, and current smokers by age, and years since giving up smoking in ex-smokers from the Omnibus survey, ${ }^{3}$ mortality rate ratios in continuing and ex-smokers provided in the UK doctors study reports, ${ }^{214}$ and UK all cause mortality rates for $2001^{15}$ to estimate current mortality rates in smokers and ex-smokers in 10 year age bands.

We then calculated the current annual number of deaths attributable to smoking by multiplying the number of current smokers in each age and sex group by the appropriate age and sex specific mortality rate. The UK doctors study provides mortality rate ratios for male smokers and recent ex-smokers only in the ages between 35 and $74,{ }^{2}{ }^{14}$ so our estimates were restricted to deaths between these ages and assume similar mortality rate ratios in men and women. We then extended this calculation for successive years in a model in which smoking prevalence in all age and sex categories reduced by either 0.4 or 1 percentage point per year for the next 10 years, adjusting the total number of smokers expected to be alive in each age and sex category at the beginning of each year, and repeating the process for each successive year. In these calculations we assumed that mortality in those who stopped smoking fell immediately to that of ex-smokers who had stopped in the previous decade. ${ }^{2}{ }^{14}$ To estimate the effect of the targets suggested to be achievable in the Wanless report ${ }^{12}$ we also modelled the effect of reductions of 1 percentage point per year for seven years followed by half a percentage point for three years; to estimate the total effect of the 
Wanless targets in those aged 35-74 years over their full 19 years, we continued this model assuming a continued half percentage point reduction per year for a further nine years. For this latter calculation we assumed that after 10 years as an ex-smoker, the mortality rate in those who stop smoking falls to that of an ex-smoker who stopped 10-20 years ago (similar to that of a non-smoker for all but those aged 65 or over). ${ }^{214}$

\section{RESULTS}

We estimate that there are currently about 6.62 million smokers aged between 35-74 in the UK (table 1); if current prevalence remains unchanged then each year approximately 69049 of these smokers will die. Table 1 also illustrates the calculation of the numbers of deaths expected to be prevented in one year by a 1 percentage point reduction in smoking prevalence, broken down by age and sex, and demonstrates that this would result in the prevention of approximately 1061 deaths of which over 600 would be in the 65-74 year age group.

Tables 2 and 3 demonstrate the numbers of deaths expected to be prevented each year, and cumulative totals over 10 years, by successive 0.4 and 1 percentage point annual reductions in smoking prevalence. Respectively these trends would result in the prevention of approximately 23192 and 57977 deaths in the 35-75 year age range over the next 10 years. Repeating the calculations using the prevalence targets proposed by Wanless ${ }^{12}$ results in an estimated cumulative total of 29458 deaths prevented in seven years by a 1 percentage point annual fall in prevalence, and an overall total of 54308 and 194493 deaths over 10 and 19 years, respectively, if this is followed by a further annual reduction by half a percentage point over the next 12 years (table 4). By 19 years, the overall prevalence of smoking in the UK would have fallen to $11 \%$.

\section{DISCUSSION}

This study demonstrates that reducing smoking prevalence in adults in the UK will prevent substantial numbers of deaths in the current adult smoking population over the next 10 years. Even assuming that the recent decline of 0.4 percentage points per year will continue for 10 more years without further intervention, the figures show that implementing measures to achieve more notable prevalence reductions has the potential to prevent tens of thousands of deaths, most of which will be in the 65-74 year age group. The return in numbers of deaths avoided is, however, likely to be much greater over the longer term, as is evident in the estimated effect of achieving the sustained reductions in prevalence outlined in the Wanless report. ${ }^{12}$ Although our estimates relate only to the UK, the method can be applied simply to smoking prevalence data for other countries.

Our figures are inevitably approximate but are more likely to be underestimates than overestimates of the true effect of these prevalence reductions for several reasons. Our
Table 2 Cumulative deaths prevented over 10 years by a 0.4 percentage point reduction in smoking prevalence per annum

\begin{tabular}{ccccc}
\hline & \multicolumn{2}{l}{ Annual lives saves } & \multicolumn{2}{c}{$\begin{array}{l}\text { Cumulative lives } \\
\text { saved }\end{array}$} \\
\cline { 2 - 5 } Year & Men & Women & Total & 425 \\
\hline 1 & 251 & 174 & 425 & 1273 \\
2 & 501 & 347 & 848 & 2545 \\
3 & 751 & 521 & 1272 & 4237 \\
4 & 998 & 694 & 1692 & 6346 \\
5 & 1243 & 866 & 2109 & 8860 \\
6 & 1480 & 1034 & 2514 & 11785 \\
7 & 1719 & 1206 & 2925 & 15141 \\
8 & 1970 & 1386 & 3356 & 18942 \\
9 & 2228 & 1573 & 3801 & 23192 \\
10 & 2487 & 1763 & 4250 & \\
\hline
\end{tabular}

Table 3 Cumulative deaths prevented over 10 years by a 1 percentage point reduction in smoking prevalence per annum

\begin{tabular}{ccccc}
\hline & \multicolumn{2}{l}{ Annual lives saved } & \multicolumn{2}{l}{$\begin{array}{l}\text { Cumulative lives } \\
\text { saved }\end{array}$} \\
\cline { 2 - 4 } Year & Men & Women & Total & 1061 \\
\hline 1 & 627 & 434 & 1061 & 3179 \\
2 & 1252 & 867 & 2119 & 6358 \\
3 & 1877 & 1302 & 3179 & 10588 \\
4 & 2496 & 1734 & 4230 & 15860 \\
5 & 3108 & 2164 & 5272 & 22146 \\
6 & 3700 & 2585 & 6286 & 29458 \\
7 & 4297 & 3014 & 7312 & 37849 \\
8 & 4925 & 3465 & 8391 & 47352 \\
9 & 5571 & 3932 & 9503 & 57977 \\
10 & 6218 & 4407 & 10625 & 5 \\
\hline
\end{tabular}

estimates exclude the extremes of age because relative risk data were not available for those aged under 35 or over 74 , and the exclusion of the older age group in particular is likely to lead to substantial underestimation. There is also likely to be further benefit from the prevalence reductions modelled (almost all of which, because most smokers start smoking in adolescence, would be achieved by smoking cessation in existing smokers) since existing evidence suggests that measures that reduce adult smoking also reduce incident smoking in young people. ${ }^{16}$ The relative risk estimates for smokers and ex-smokers we used ${ }^{214}$ are among the most authoritative available, and are derived from a UK population group, but like many smoking cohort studies the data are limited to men. We have therefore assumed similar risks in women, and recent data from Hong Kong and the USA suggest that this assumption is reasonable. ${ }^{17-19}$ The fact that the relative risks in the British doctors study are derived from

Table 1 Estimated deaths prevented over one year by a 1 percentage point reduction in smoking prevalence

\begin{tabular}{|c|c|c|c|c|c|c|c|c|c|c|c|}
\hline \multirow[b]{2}{*}{ Initial age } & \multicolumn{2}{|c|}{$\begin{array}{l}\text { Initial smoking } \\
\text { prevalence \% }\end{array}$} & \multicolumn{2}{|c|}{$\begin{array}{l}\text { Estimated number } \\
\text { of smokers }\end{array}$} & \multicolumn{2}{|c|}{$\begin{array}{l}\text { Estimated annual } \\
\text { mortality per } 1000 \\
\text { smokers }\end{array}$} & \multicolumn{2}{|c|}{$\begin{array}{l}\text { Estimated annual mortality } \\
\text { per } 1000 \text { ex-smokers } \\
\text { (stopped in last } 10 \text { years) }\end{array}$} & \multicolumn{3}{|c|}{$\begin{array}{l}\text { Deaths prevented by } 1 \% \text { point } \\
\text { reduction in smoking prevalence }\end{array}$} \\
\hline & Men & Women & Men & Women & Men & Women & Men & Women & Men & Women & Total \\
\hline $35-44$ & 34 & 26 & 1473706 & 1155170 & 2.2 & 1.4 & 1.7 & 1.0 & 22 & 18 & 40 \\
\hline $45-54$ & 26 & 23 & 1002219 & 901994 & 6.8 & 4.5 & 4.3 & 2.8 & 96 & 67 & 163 \\
\hline $55-64$ & 24 & 20 & 734662 & 631543 & 18.4 & 12.0 & 14.1 & 9.2 & 132 & 88 & 220 \\
\hline $65-74$ & 13 & 16 & 299069 & 421687 & 58.1 & 35.2 & 41.7 & 25.3 & 377 & 261 & 638 \\
\hline Total & & & 3509656 & 3110394 & & & & & 627 & 434 & 1061 \\
\hline
\end{tabular}


relatively old cohorts of smokers is likely to have led to some underestimate of mortality, since the British study ${ }^{2}$ and various other recent analyses ${ }^{17} 2021$ suggest that risks are actually higher in more recent cohorts, possibly because of starting to smoke at a younger age. ${ }^{2}$ On the other hand our assumption that smokers who quit immediately assume the death rate of an ex-smoker will have led to some overestimation of the number of deaths prevented, but this is unlikely to have been a major influence on the longer term totals.

Experience in other countries has established that in the short term at least, coordinated population measures to encourage smoking cessation can deliver additional annual reductions in smoking prevalence over and above the underlying trend, and of the order of magnitude assessed in this study. In Massachusetts the introduction of mass media smoking cessation campaigns, smoking cessation services, and various community initiatives to promote cessation reduced prevalence by 0.43 percentage points per annum between 1992 and 1999, a period in which the prevalence of smoking in the rest of the USA actually increased..$^{22}$ In California, mass media health promotions, increased tobacco tax, public smoke-free policies, and other local community initiatives reduced prevalence over five years in the early 1990s by about 0.9 percentage points per year more than in the rest of the USA. ${ }^{23}$ This trend has translated into a substantial fall in mortality, ${ }^{24}$ and a significant reduction in incident smoking in young people. ${ }^{16}$ In New York a combination of higher taxation, cessation services, and smoke-free public places is reported to have reduced smoking prevalence by nearly 3 percentage points in one year. ${ }^{25}$

In terms of tobacco control policy the UK government has implemented a comprehensive advertising ban, continues to develop cessation services, and is implementing larger and more graphic health warnings on cigarette packs. The additional policies necessary to maximise reductions in prevalence are therefore further and substantial investment in sustained health promotion campaigns, ${ }^{5-8}$ price increases above the rate of inflation, ${ }^{56}$ and making all public and work places smoke-free. ${ }^{6}$ Smoke-free workplaces alone would, even after allowing for the fact that many workplaces are already smoke-free, ${ }^{1}$ reduce the absolute prevalence of

Table 4 Cumulative deaths prevented over 19 years presuming a 1 percentage point reduction in smoking prevalence per annum for 7 years, then $0.5 \%$ for 12 years

\begin{tabular}{ccccc}
\hline & \multicolumn{3}{l}{ Annual lives saves } & \\
Year & Men & Women & Total & $\begin{array}{l}\text { Cumulative lives } \\
\text { saved }\end{array}$ \\
\cline { 2 - 5 } 1 & 627 & 434 & 1061 & 1061 \\
2 & 1252 & 867 & 2119 & 3179 \\
3 & 1877 & 1302 & 3179 & 6358 \\
4 & 2496 & 1734 & 4230 & 10588 \\
5 & 3109 & 2164 & 5272 & 15860 \\
6 & 3700 & 2585 & 6286 & 22146 \\
7 & 4297 & 3014 & 7312 & 29458 \\
8 & 4554 & 3223 & 7776 & 37234 \\
9 & 4833 & 3446 & 8279 & 45513 \\
10 & 5120 & 3676 & 8795 & 54308 \\
11 & 5882 & 4208 & 10090 & 64398 \\
12 & 6743 & 4805 & 11547 & 75945 \\
13 & 7576 & 5393 & 12970 & 88914 \\
14 & 8379 & 5967 & 14346 & 103261 \\
15 & 9167 & 6537 & 15705 & 118965 \\
16 & 9970 & 7126 & 17096 & 136061 \\
17 & 10758 & 7709 & 18467 & 154528 \\
18 & 11513 & 8269 & 19782 & 174310 \\
19 & 11706 & 8477 & 20183 & 194493 \\
\hline
\end{tabular}

What this paper adds

Implementing policies to reduce smoking prevalence by $1 \%$ per year for 10 years in the UK would prevent over 57000 deaths in that period. A more sustained reduction in prevalence of $1 \%$ per year for seven years, and then $0.5 \%$ per year for 12 years (as proposed in the recent Wanless report to the UK Chancellor of the Exchequer) would prevent over 54000 deaths in 10 years and over 190000 deaths in 19 years. Reductions in prevalence of this order of magnitude are achievable in the UK by the implementation of tobacco control policies of proven efficacy. Failure to adopt these population policies therefore represents a substantial missed opportunity to improve public health.

smoking among the current UK workforce by at least 1 percentage point, ${ }^{9}$ and would have a further though less clearly quantified impact on smoking prevalence and uptake in the wider population. ${ }^{9}$ A $10 \%$ increase in cigarette price through tax increases, assuming a price elasticity of between -0.3 and -0.5 , and also assuming effective controls on price competition from smuggling and illicit distribution of cigarettes, would reduce prevalence by between 3 and 5 percentage points. ${ }^{6}$ Graphic pack warnings are likely to have a further modest impact, ${ }^{6}$ and depending on the impact of all of these initiatives, adding intensive and sustained mass media health promotion campaigns would probably decrease prevalence by between 2 and 4 percentage points. ${ }^{6}{ }^{8}$ These policies are all most effective when implemented together, ${ }^{11}$ and we believe could therefore achieve the 10 percentage point reduction over 10 years modelled in this study-a reduction that is only slightly greater than the 10 year targets considered to be achievable in the Wanless report. ${ }^{12}$ Since the majority of deaths prevented by these policies would be in relatively deprived social groups, among whom the prevalence and intensity of smoking is currently highest, ${ }^{126}$ these measures would also have a substantial impact on social inequalities in health.

Although reductions in prevalence of the magnitude outlined above would have a pronounced impact on mortality and cut the number of smokers in the UK by up to half, it is clearly also important to consider other means of reducing morbidity and mortality from tobacco use, and specifically the provision of alternative and safer sources of nicotine. Medicinal nicotine is the safest alternative but needs to be licensed, formulated, and market tested as a direct alternative to continued smoking rather than as a cessation therapy. Consideration should also be given to allowing limited market freedoms to alternative tobacco based products, such as Swedish oral smokeless tobacco (snus), since this product has a strongly favourable profile of adverse effects relative to cigarettes $^{27-29}$ and appears to be widely acceptable as an alternative to cigarettes, particularly to men. By 2002, 14\% of Swedish male smokers had switched from smoking to using snus, and the prevalence of smoking in Swedish men had fallen to only $15 \%{ }^{28}$ This appears to have had a substantial beneficial impact on lung cancer rates in Sweden, which are now lower than in any comparable developed nation. ${ }^{28}$ Making safer nicotine sources available in the UK as part of a controlled harm reduction strategy, even if some of these products are not entirely risk-free, could therefore generate substantial further reductions in smoking prevalence and related harm. ${ }^{30-32}$

All of the interventions outlined above have the potential to reduce immediately and in due course substantially the prevalence of cigarette smoking in the UK, and thus to prevent much of the morbidity and mortality currently 
caused by regular smoking. However, while the Scottish Parliament has recently announced legislation to make public places in Scotland smoke-free in 2006, the recently published UK government White Paper on public health ${ }^{33}$ promises only delayed and incomplete implementation of smoke-free policies in public places in the rest of the UK, and provides no firm commitments to tax increases or spending on health promotion. These are effective policies that need to be implemented now.

\section{Authors' affiliations}

S Lewis, University of Nottingham, Division of Respiratory Medicine, City Hospital, Nottingham, UK

D Arnott, Action on Smoking and Health, London, UK

C Godfrey, Centre for Health Economics, University of York, York, UK J Britton, University of Nottingham, Division of Epidemiology and Public Health, City Hospital, Nottingham, UK

Competing interests: John Britton has received a speaker's honorarium for speaking at a conference organised by a manufacturer of smoking cessation therapies, and has received consultation payments from several companies involved in smoking cessation. He also led a clinical trial of nicotine replacement therapy funded by Pharmacia. Sarah Lewis, Deborah Arnott and Christine Godfrey have no competing interests.

Ethics approval was not required for this study, which is a secondary analysis of published data.

\section{REFERENCES}

1 Lader D, Goddard L. Smoking-related behaviour and attitudes, 2003. London: Office for National Statistics, 2004.

2 Doll R, Peto R, Boreham J, et al. Mortality in relation to smoking: 50 years' observations on male British doctors. BMJ 2004;328:1519-33.

3 Royal College of Physicians. Nicotine addiction in Britain. A report of the Tobacco Advisory Group of the Royal College of Physicians. London: Royal College of Physicians of London, 2000.

4 Jarvis MJ. Monitoring cigarette smoking prevalence in Britain in a timely fashion. Addiction 2003;98:1569-74.

5 Hu TW, Sung HY, Keeler TE. Reducing cigarette consumption in California: tobacco taxes vs an anti-smoking media campaign. Am J Public Health 1995;85:1218-22.

6 Levy DT, Chaloupka F, Gitchell J. The effects of tobacco control policies on smoking rates: a tobacco control scorecard. J Public Health Manag Pract 2004; 10:338-53.

7 Siegel M. Mass media antismoking campaigns: a powerful tool for health promotion. Ann Intern Med 1998; 129:128-32.

8 Hopkins DP, Briss PA, Ricard CJ, et al. Reviews of evidence regarding interventions to reduce tobacco use and exposure to environmental tobacco smoke. Am J Prev Med 2001;20:16-66.

9 Fichtenberg CM, Glantz SA. Effect of smoke-free workplaces on smoking behaviour: systematic review. BMJ 2002;325:188-91.
10 Levy D, Gitchell J, Chaloupka F. The effects of tobacco control policies on smoking rates: a tobacco control scorecard. Calverton, Maryland: PIRE Working Paper, 2003.

11 World Bank. Tobacco control at a glance, World Bank, 2003. http:// wwwl .worldbank.org/tobacco/pdf/AAG\%20Tobacco\%206-03.pdf.

12 Wanless D. Securing good health for the whole population. London: HMSO, 2004.

13 National Statistics. Census 2001 population report. National Statistics, 2002. www.statistics.gov.uk/census2001/pop2001/ united_kingdom_ages.asp.

14 Doll R, Peto R, Wheatley K, et al. Mortality in relation to smoking: 40 years' observations on male British doctors. BMJ 1994;309:901-11.

15 National Statistics. Age specific death rates: by sex, 2001: Regional Trends 38. National Statistics, 2004. www.statistics.gov.uk/StatBase/Expodata/ Spreadsheets/D7673.xls.

16 Chen XG, Li GH, Unger JB, et al. Secular trends in adolescent never smoking from 1990 to 1999 in California: an age-period-cohort analysis. Am J Public Health 2003:93:2099-104.

17 Lam TH, Ho SY, Hedley AJ, et al. Mortality and smoking in Hong Kong: casecontrol study of all adult deaths in 1998. BMJ 2001;323:361-2.

18 Harris JE, Thun MJ, Mondul AM, et al. Cigarette tar yields in relation to mortality from lung cancer in the cancer prevention study II prospective cohort, 1982-8. BMJ 2004;328:72.

19 Flanders WD, Lally CA, Zhu BP, et al. Lung cancer mortality in relation to age, duration of smoking, and daily cigarette consumption: results from Cancer Prevention Study II. Cancer Res 2003;63:6556-62.

20 Phillips AN, Wannamethee SG, Walker M, et al. Life expectancy in men who have never smoked and those who have smoked continuously: 15 year follow up of large cohort of middle aged British men. BMJ 1996;313:907-8.

21 Sunyer J, Lamarca R, Alonso J. Smoking after age 65 years and mortality in Barcelona, Spain. Am J Epidemiol 1998;148:575-80.

22 Biener L, Harris JE, Hamilton W. Impact of the Massachusetts tobacco control programme: population based trend analysis. BMJ 2000;321:351-4.

23 Pierce JP, Gilpin EA, Emery SL, et al. Has the California tobacco control program reduced smoking? JAMA 1998;280:893-9.

24 Fichtenberg CM, Glantz SA. Association of the California tobacco control program with declines in cigarette consumption and mortality from heart disease. N Engl J Med 2000;343:1772-7.

25 Gottlieb S. New York's war on tobacco produces record fall in smoking. BMJ 2004;328: 1222.

26 Jarvis MJ, Wardle J. Social Patterning of individual health behaviours: the case of cigarette smoking. In: Marmot M, Wilkinson R, eds. Social determinants of health. Oxford: Oxford University Press, 1999.

27 Fagerstrom KO, Schildt EB. Should the European Union lift the ban on snus? Evidence from the Swedish experience. Addiction 2003;98:1191-5.

28 Foulds J, Ramstrom L, Burke M, et al. Effect of smokeless tobacco (snus) on smoking and public health in Sweden. Tobacco Control 2003;12:349-59.

29 Critchley JA, Unal B. Health effects associated with smokeless tobacco: a systematic review. Thorax 2003;58:435-43.

30 Tobacco Advisory Group of the Royal College of Physicians. Protecting smokers, saving lives. The case for a tobacco and nicotine regulatory authority. London: Royal College of Physicians, 2002.

31 Kozlowski LT, Strasser AA, Giovino GA, et al. Applying the risk/use equilibrium: use medicinal nicotine now for harm reduction. Tobacco Control 2001; 10:201-3.

32 Sumner W II. Estimating the health consequences of replacing cigarettes with nicotine inhalers. Tobacco Control 2003;12:124-32.

33 Department of Health. Choosing health. Making healthy choices easier. London: Department of Health, 2004. 